\title{
Genome-resolved investigation of potential new mercury-methylating marine bacterial phyla
}

HEYU LiN ${ }^{1}$, DAVID B. ASChER ${ }^{1,2}$, YOOCHAN MYUNG ${ }^{1,2}$, CARL H. LAMBORG ${ }^{3}$, STEVEN J. HALlaM ${ }^{4}$, CAITLIN M. GIONFRIDDO $^{5}$, RYAN R. WICK ${ }^{6}$, KATHRYN E. HOLT ${ }^{6,7}$ AND $\underline{\text { JOHN W. MOREAU }}^{1,8, *}$

${ }^{1}$ The University of Melbourne, Melbourne, VIC, AUS

${ }^{2}$ Baker Institute, Melbourne, VIC, AUS

${ }^{3}$ University of Santa Cruz, CA, USA

${ }^{4}$ University of British Columbia, BC, CAN

${ }^{5}$ Oak Ridge National Laboratory, TN, USA

${ }^{6}$ Monash University, VIC, AUS

${ }^{7}$ London School of Hygiene \& Tropical Medicine, UK

${ }^{8}$ University of Glasgow, UK; *john.moreau@gla.ac.uk

Microbes that can transform aqueous mercury $(\mathrm{Hg})$ into methylmercury $(\mathrm{MeHg})$ require the gene pair hgcAB, previously associated only with anaerobic bacteria. Using genome-resolved metagenomic analyses, we found potential new Hg-methylating bacterial phyla in Antarctic seawater and Canadian coastal waters associated with variable degrees of oxygenation. Among these new phyla was a clade of Marinimicrobia with evidence to suggest acquisition of $h g c A B$ through lateral gene transfer, as well as members of Calditrichaeota, SAR324 and Nitrospina. HgcAB-carrying Marinimicrobia and Nitrospina appear to be environmentally widespread across ocean sites, with major roles to play in marine biogeochemical cycling. Our findings suggest a broadened habitat range for $\mathrm{Hg}$-methylating microorganisms than previously surmised. Under plausible climate change scenarios, these findings imply a need to assess possible negative ecosystem and human health impacts from increased mercury methylation potential. 